Gut, 1978, 19, 827-830

\title{
Relationship of the constituents of bile to biliary peritonitis in the rat
}

\author{
E. M. WALKER ${ }^{1}$ AND H. ELLIS
}

From the Westminster Hospital, London

SUMMARY The local action of bile salts has been associated with a wide variety of gastrointestinal diseases. This paper describes an animal model to determine which of the major solid components of bile are responsible for peritoneal destruction in biliary peritonitis. In the rat, bile salts within the peritoneal cavity cause peritonitis but cholesterol and lecithin are without deleterious effect.

The local action of bile salts has been associated with gastritis, gastric ulcer, pancreatitis, diarrhoea associated with ileal disease or resection, some cases of non-specific diarrhoea, and some of the features of cholestasis (Datta and Sherlock, 1963; Hansson, 1967; Rowe, 1967; Schoenfield et al., 1967; Cooper and Jandle, 1968; Davenport, 1968; Overholt and Pollard, 1968; Rhodes, 1972). Their toxicity may be due in part to the effects of their detergent properties on tissues not adapted to their presence.

The morbidity and mortality of biliary peritonitis has diminished with the introduction of early surgical drainage and peritoneal lavage. McWilliams (1911) reported $51 \%$ mortality in a review of 108 cases of biliary perforation. Various authors since then have given mortality figures for biliary peritonitis of $70 \%$ (MacDonald, 1966), 50\% (Ellis and Cronin, 1960), 40\% (Ellis and Adair, 1974), 39\% (Essenhigh, 1968), 29\% (McEarchern and Sullivan, 1963), and $25 \%$ (Leborgne et al., 1972). Lilley et al. (1974) reviewed 53 infants with spontaneous perforation of the extrahepatic bile ducts with a $20 \%$ mortality. In these patients the peritonitis was usually sterile, indicating that the constituents of bile rather than bacterial contamination was responsible for peritonitis. In adults the role of in fection in biliary peritonitis remains unclear.

This paper presents an experimental study of the effects of the individual constituents of bile on the peritoneum and compares them with the action of sterile bile itself.

\footnotetext{
${ }^{1}$ Address for correspondence: Mr E. M. Walker, The General Hospital, Nottingham.
}

Received for publication 9 March 1978

\section{Methods}

Female Sprague Dawley rats weighing between 150 and $220 \mathrm{~g}$ were used throughout these experiments.

The main organic solids of bile were prepared for intraperitoneal injection in the following manner.

\section{BILE SALTS}

A preparation of crude ox bile extract, sodium choleate (Sigma Chemical Company), was dissolved in $0.9 \%$ saline to a concentration of $1800 \mathrm{mg} / 100 \mathrm{ml}$, similar to the concentration of total human bile salts in hepatic duct bile, and passed through a Swinnex 25 millipore bacterial filtre.

CHOLESTEROL

Cholesterol is insoluble in water but soluble in vegetable oils. Dry cholesterol crystals (BDH 43011) were dissolved in sterile arachis oil to a concentration of $130 \mathrm{mg} / 100 \mathrm{ml}$, similar to the concentration of cholesterol in human bile. Microscopy following centrifugation of the solution confirmed the absence of remaining cholesterol crystals.

\section{PHOSPHOLIPID}

Egg lecithin (BDH 29053) was emulsified in normal saline to a concentration of $700 \mathrm{mg} / 100 \mathrm{ml}$, again similar to the concentration found in the human common bile duct.

\section{RAT BILE}

Bile from normal rats was collected by ligation of the common bile duct and aspiration of bile from the dilated duct at necropsy one week later. Subsequent microscopy and culture of this bile showed it to be sterile.

Forty rats were divided into four equal groups. 
The animals in each group were given an intraperitoneal injection of $1 \mathrm{ml}$ sterile rat bile, $1 \mathrm{ml}$ bile salt solution, $1 \mathrm{ml}$ cholesterol solution in arachis oil, or $1 \mathrm{ml}$ lecithin emulsion. The animals were killed at intervals of up to 21 days, and sections of the abdominal wall submitted to histological examination. Specimens of the peritoneum were examined by the Hautchen technique, which allows the surface layer of cells to be peeled off from the underlying muscle and mounted flat on a microscopic slide to provide an en-face view of the peritoneum (Raftery, 1973).

\section{Results}

All animals survived until they were killed.

INTRAPERITONEAL BILE

One millilitre of sterile rat bile injected into the peritoneal cavity provokes severe peritonitis within eight hours. Macroscopically the peritoneum loses its normal glistening appearance, and a peritoneal exudate rich in lymphocytes and polymorphonuclear leucocytes is formed. The peritoneum and subperitoneal muscle become oedematous, with infiltration of inflammatory cells (Fig. 1). Healing occurs, and within 14 days a normal layer of peritoneal cells may be seen (Fig. 2).

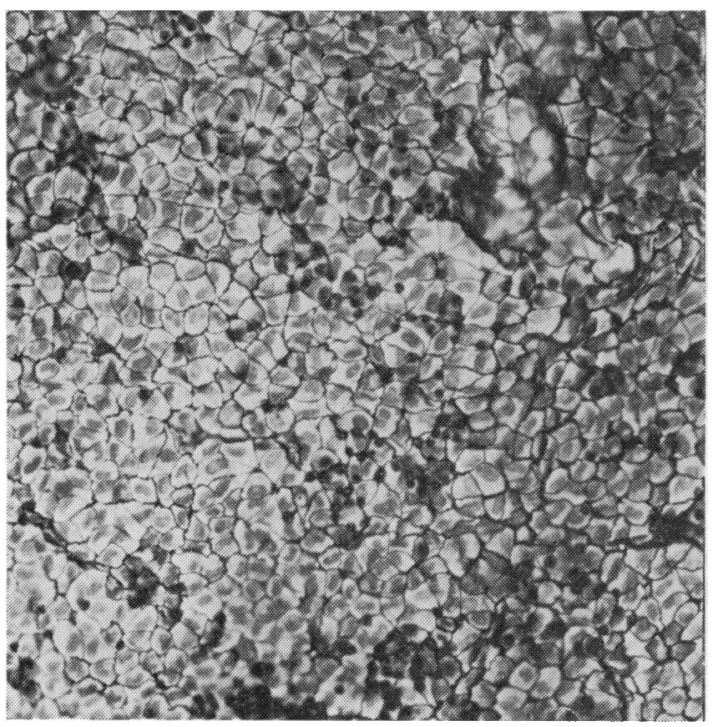

Fig. 1 Hautchen preparation of peritoneum 48 hours after injection of bile. The peritoneum is intact but covered with inflammatory cells. $\times 125$.

INTRAPERITONEAL BILE SALTS

One millilitre of a solution of ox bile salts in 'physiological' concentration destroys the peritoneum to a

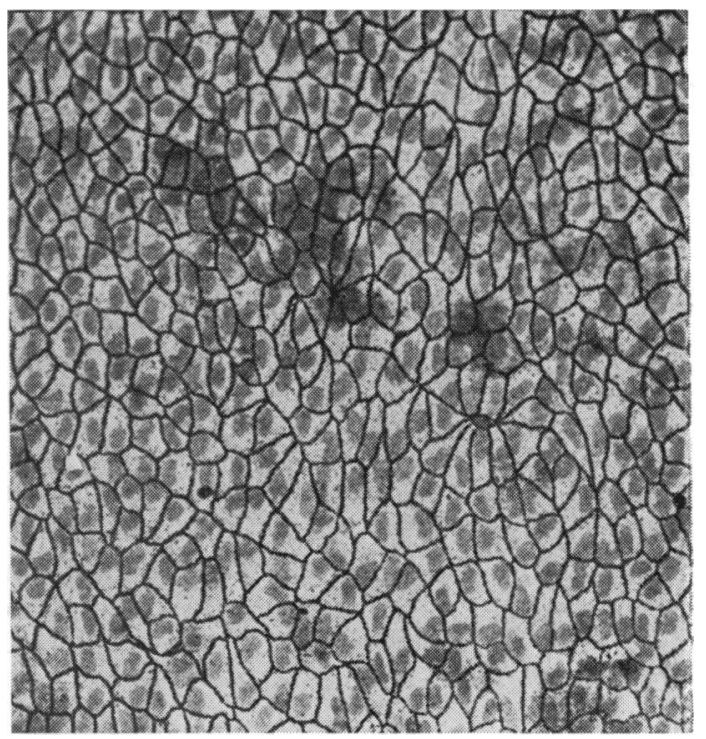

Fig. 2 Normal peritoneum, 14 days after the injection of bile. $\times 125$.

greater extent than rat bile alone. The subperitoneal muscle, at first oedematous, becomes necrotic, and finally heals by fibrosis. Macrophages appear on the surface of the peritoneum but within seven days the peritoneum has returned to normal (Figs. 3, 4).

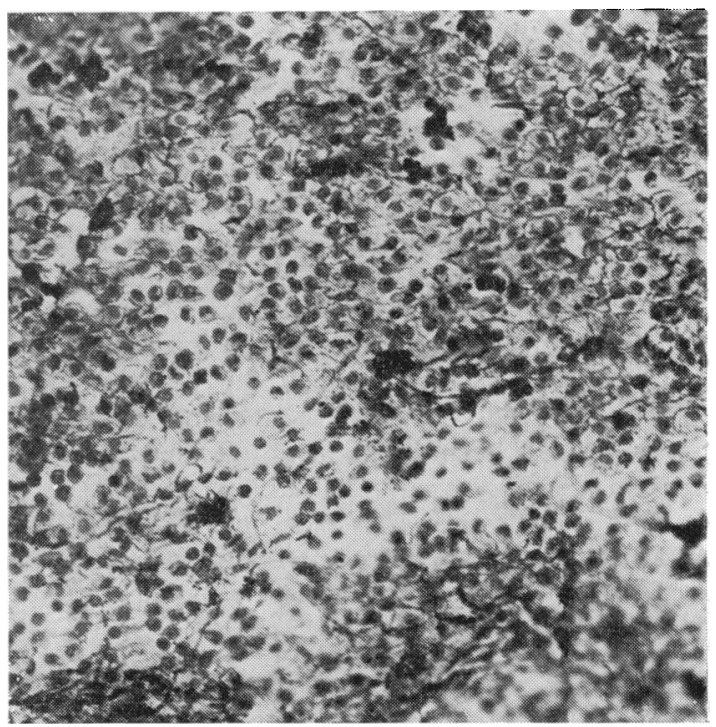

Fig. 3 Peritoneal inflammation and destruction 24 hours after injection of bile salt. $\times 125$. 


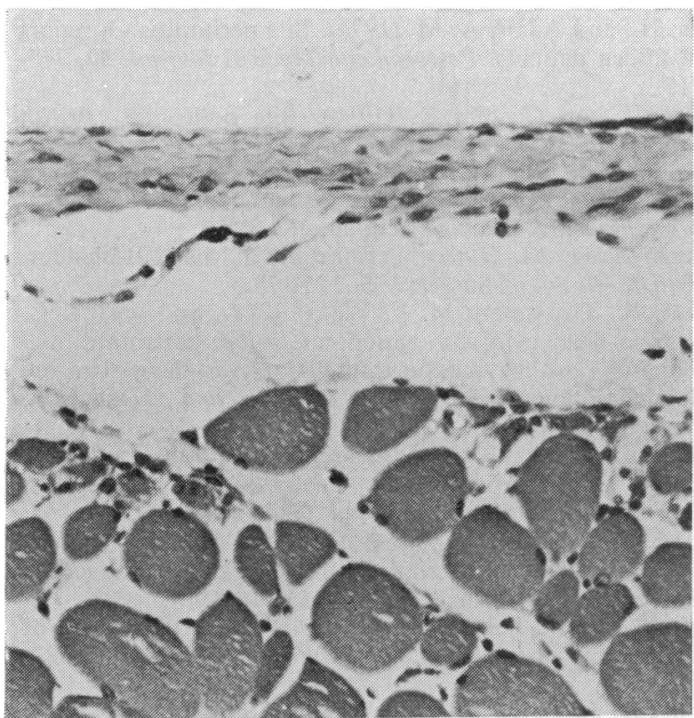

Fig. 4 Section showing oedematous peritoneum and muscle 48 hours after bile salt injection. $\times 125$.

INTRAPERITONEAL CHOLESTEROL

An intraperitoneal injection of sterile arachis oil has been shown by previous experiments to provoke little inflammatory response and no destruction of peritoneum. Cholesterol dissolved in arachis oil to a 'physiological' concentration provokes a mild inflammatory reaction around the oily droplets, but the peritoneal cell walls are clearly seen intact (Fig. 5).

\section{INTRAPERITONEAL PHOSPHOLIPID}

A 'physiological' concentration of lecithin emulsified in $1 \mathrm{ml}$ normal saline and injected into the peritoneal cavity produces no inflammatory reaction and no destruction of peritoneum or subperitoneal muscle (Fig. 6).

\section{Discussion}

The rat provides a suitable animal model in which to study the effects of intraperitoneal irritants. However, it must be appreciated that the rat peritoneum may handle infection and chemical irritants in a different manner from the human peritoneum. Hautchen preparations have been used to observe the regeneration of peritoneal cells after excision of areas of peritoneum (Raftery, 1973). Much more can be learned from viewing a single layer of surface cells than by cutting serial sections, but the technique does have drawbacks (Eskeland 1966). It is difficult to obtain good photomicrographs since cells embedded in the celloidin do not always lie in the

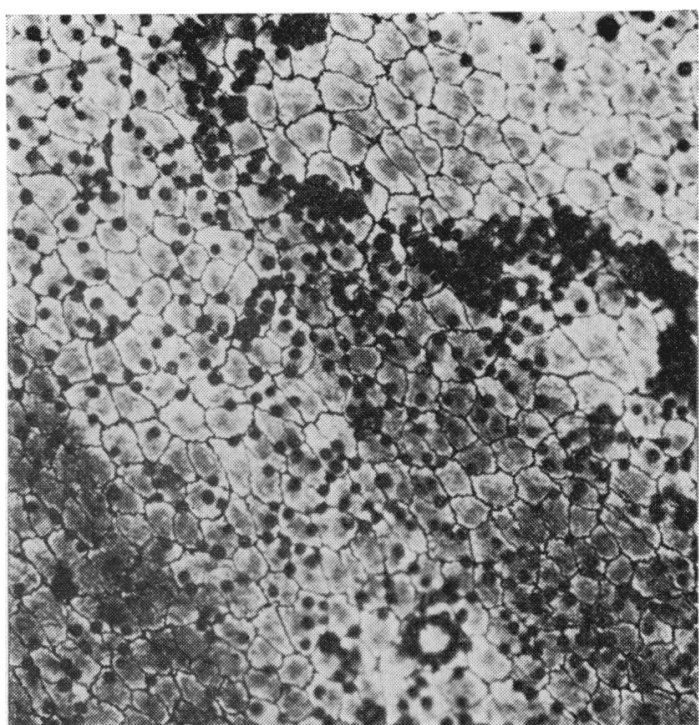

Fig. 5 Inflammatory cells surrounding oil drops, 24 hours after cholesterol injection. There is no peritoneal destruction. $\times 125$.

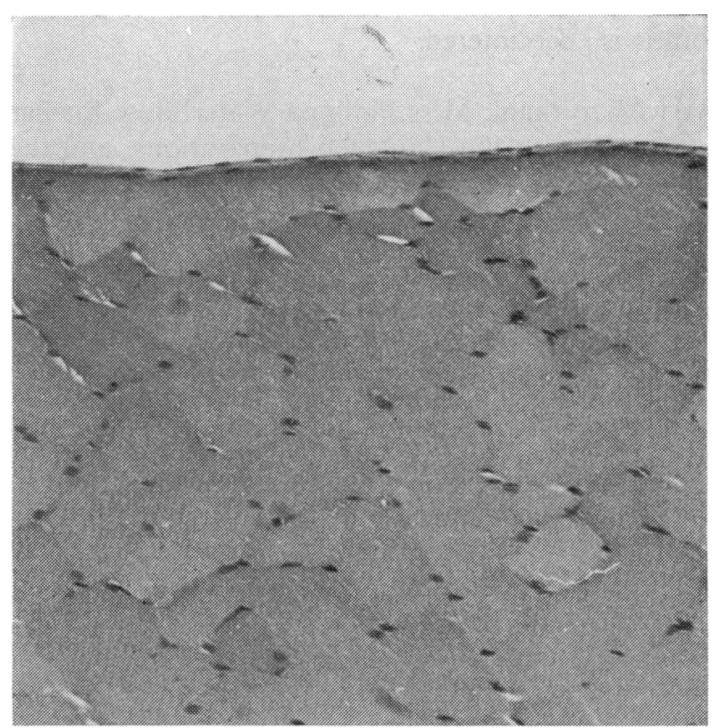

Fig. 6 Forty-eight hours after lecithin injection the peritoneum is normal. $\times 125$.

same plane; also more than one layer of cells may adhere to the celloidin in the early stages of wound healing.

Within the narrowly defined limits of the enterohepatic circulation bile salts are essential to health. If they escape from this circulation their detergent properties may have harmful effects (Kappas and 
Palmer, 1963; Hofmann and Small, 1967; Low-Beer et al., 1970). The lytic effects of certain steroids, including bile salts, is well established (Andrews and Aronsohn, 1936; Womack and Brickner, 1940; Grant et al., 1951), However, cholesterol is a potent inhibitor of haemolysis induced by bile salts (Berliner and Schoenheimer, 1930). This may account for our finding that destruction of peritoneum by bile salt solution is greater than by bile.

The role of bile salts in the destruction of peritoneal cells in biliary peritonitis has not been previously reported. The experiments described in this paper clearly indicate that bile salts destroy the mesothelial cells of the rat peritoneum, whereas cholesterol results in inflammation but no destruction of the peritoneum. Phospholipid appears to provoke little peritoneal reaction.

The mortality of biliary peritonitis has been reduced in recent years by early drainage and lavage of the peritoneal cavity. However, the mortality remains unacceptably high. Bile salts are soluble in saline, and, as they are the main solid constituent of bile to cause peritoneal destruction, every effort should be made to wash bile out of the peritoneal cavity with saline in patients where biliary peritonitis is encountered.

We wish to thank Miss Philippa Waterhouse for her assistance with the Hautchen preparations, and the Department of Photography of the General Hospital, Nottingham, for photographic assistance.

\section{References}

Andrews, E., and Aronsohn, H. G. (1936). Relative toxicity of different bile salts on the normal gall bladder. Proceedings of the Society of Experimental Biology, 34, 765767.

Berliner, F., and Schoenheimer, R. (1938). Hemolytic and antihemolytic properties of bile acids and sterols in relation to their structure. Journal of Biological Chemistry, 124, 525-541.

Cooper, R. A., and Jandl, J. H. (1968). Bile salts and cholesterol in the pathogenesis of target cells in obstructive jaundice. Journal of Clinical Investigation, 47, 809-822.

Datta, D. V., and Sherlock, S. (1963). Treatment of pruritis of obstructive jaundice with cholestramine. British Medical Journal, 1, 216-219.

Davenport, H. W. (1968). Destruction of the gastric mucosal barrier by detergents and urea. Gastroenterology, 54, 175181.
Ellis, H., and Adair, A. M. (1974). Bile peritonitis - a report of fifteen patients. Postgraduate Medical Journal, 50, 713717.

Ellis, H., and Cronin, K. (1960). Bile peritonitis. British Journal of Surgery, 48, 166-171.

Eskeland, G. (1966). Regeneration of parietal peritoneum in rats. I. A light microscopial study. Acta Pathologica et Microbiologica Scandinavica, 68, 355-378.

Essenhigh, D. M. (1968). Perforation of the gall-bladder. British Journal of Surgery, 55, 175-178.

Grant, R., Grossman, M. I., Wang, K. J., and Ivy, A. C. (1951). The cytolytic action of some gastrointestinal secretions and enzymes on epithelial cells of the gastric and duodenal mucosa. Journal of Cellular and Comparative Physiology, 37, 137-161.

Hansson, K. (1967). Experimental and clinical studies in aetiologic role of bile reflux in acute pancreatitis. Acta Chirurgica Scandinavica, suppl., 375, 43-102.

Hofmann, A. F., and Small, D. M. (1967). Detergent properties of bile salts: correlation with physiological function. Annual Review of Medicine, 18, 333-376.

Kappas, A., and Palmer, R. H. (1963). Selected aspects of steroid pharmacology. Pharmacological Reviews, 15, 123167.

Leborgne, J., Le Neel, J. C., Visset, J., and Mousseau, M. (1972). Les peritonites biliares. Annales de Chirurgie, 26, 153-160.

Lilly, J. R., Weintraub, W. H., and Altman, R. P. (1974). Spontaneous perforation of the extrahepatic bile ducts and bile peritonitis in infancy. Surgery, 75, 664-673.

Low-Beer, T. S., Schneider, R. E., and Dobbins, W. O. (1970). Morphological changes of the small-intestinal mucosa of guinea pig and hamster following incubation in vitro and perfusion in vivo with unconjugated bile salts. Gut, 11, 486-492.

MacDonald, J. A. (1966). Perforation of the gallbladder associated with acute cholecystitis. Annals of Surgery, 164, 849-852.

McEarchern, C. G., and Sullivan, R. E. (1963). Perforation of the gall bladder. Analysis of 21 cases. Archives of Surgery, 87, 489-492.

McWilliams, C. A. (1911). Acute spontaneous perforation of the biliary system into the free peritoneal cavity. Annals of Surgery, 55, 235-263.

Overholt, B. F., and Pollard, H. M. (1968). Acid diffusion into the human gastric mucosa. Gastroenterology, 54, 182189.

Raftery, A. T. (1973). Regeneration of parietal and visceral peritoneum. British Journal of Surgery, 60, 293-299.

Rhodes, J. (1972). Etiology of gastric ulcer. Gastroenterology, 63, 171-182.

Rowe, G. G. (1967). Control of tenesmus and diarrhoea by cholestyramine administration. Gastroenterology, 53, 1006.

Schoenfield, L. J., Sjövall, J., and Perman, E. (1967). Bile acids on the skin of patients with pruritic hepatobiliary disease. Nature, 213, 93-94.

Womack, N. A., and Brickner, E. M. (1940). Pathological changes in the gallbladder wall due to action of bile. Proceedings of the Society of Experimental Biology, 45, 710-712. 